\title{
Process Systems Engineering for Decarbonisation Strategies and Systems
}

\author{
Viknesh Andiappan ${ }^{1}$ - Yoke Kin Wan ${ }^{2}$ - Denny K. S. Ng ${ }^{1}$ \\ Accepted: 29 March 2021 / Published online: 27 April 2021 \\ (C) The Author(s), under exclusive licence to Springer Nature Singapore Pte Ltd. 2021
}

At the 2015 United Nations international climate change conference in Paris (COP21), 196 countries committed to limit global warming to well below $2^{\circ} \mathrm{C}$, preferably to $1.5^{\circ} \mathrm{C}$, compared to pre-industrial levels (UN Framework Convention on Climate Change 2015). At the conference, many countries established national actions to reduce emissions. These countries identified that low carbon technologies (e.g. renewable energy, biofuels) would be essential to reducing emissions in the future (UN Framework Convention on Climate Change 2015). However, current plans and pace of progress to deploy low carbon technologies are still far from sufficient. This is because many countries face challenges to find cost-effective ways to deploy low carbon technologies to meet the commitments made at COP21. Process Systems Engineering (PSE) can play an essential role to address the abovementioned challenges. PSE offers tools can be used to support high-level policy and operational decisions for deployment of low carbon technologies.

PSE is a field of research that is concerned with the development of systematic tools for synthesis, design, and operation. At the synthesis level, screening of technologies can be performed to determine the optimal technologies and system integration. At the design level, technical specifications (e.g. capacity, operating limits) are to be defined for the

Viknesh Andiappan

v.murugappan@hw.ac.uk

Yoke Kin Wan

YokeKin.Wan@nottingham.edu.my

Denny K. S. Ng

Denny.Ng@hw.ac.uk

1 School of Engineering and Physical Sciences, Heriot-Watt University Malaysia, No. 1, Jalan Venna P5/2, Precinct 5, 62200 Putrajaya, Malaysia

2 Department of Chemical and Environmental Engineering, University of Nottingham Malaysia, Broga Road, 43500 Semenyih, Selangor, Malaysia technologies selected during the synthesis level. Lastly, the optimal operation mode (e.g. temperatures, pressures flow rates, uncertainties) is to be defined at the operational level given that the synthesis and design have been performed. In the past decades, most of the works have attempted synthesis, design, and operation levels in an isolation from one another. It is well documented that several studies focused on synthesis and design levels without considering their effect on the operation level. Thus, operations may experience several uncertainties (e.g. varying supply and demand profiles, fluctuating prices, equipment failure) that may render networks infeasible for operation (Andiappan 2017). This would induce a need to reconsider key design decisions made initially, resulting in a large amount of rework and extra cost for completion of the design. In this respect, there is a need to consider all three levels in an integrated manner.

This Special Issue on "Process Systems Engineering for Decarbonisation Strategies and Systems" curated novel advances in the development of PSE tools to address integrated consideration of synthesis, design, and operation of decarbonisation strategies and systems. In this issue, a total of nine papers were accepted for publication after a comprehensive peer review process. These accepted papers covered strategies to design sustainable solvents and systems that utilise renewable energy sources. A brief overview of these papers is as follows.

Firstly, Ten et al. (2021) presented a systematic framework to design sustainable solvents for liquid-liquid extraction processes that are less toxic and harmful to the environment. The proposed framework utilised a computer-aided molecular design (CAMD) technique to synthesise and design alternative solvents for liquid-liquid extractions. To ensure that the designed solvent is safer for users, safety and health parameters are included as design criteria.

Aside from solvent design, several papers in this issue presented strategies to design systems that utilise renewable sources. Two of the papers in this special issue presented PSE tools to design systems that utilise solar energy. The first 
paper by Lizárraga-Morazán and Picón-Núñez (2021) presented a robust approach to design a low temperature-based solar thermal utility system with the consideration of the availability of land area for installation. This work used stochastic multi-objective optimisation to optimise the trade-off between the solar collector geometry and utility system network configuration. On the other hand, Leng et al. (2021) proposed a new method to investigate solar fraction, stagnation, and economic performance of a solar thermal integration system. The proposed method involves a four-step procedure which includes establishing a daily heat storage profile, analysing system performance, reducing stagnation, and performing techno-economic analysis. Besides solar, Hernandez et al. (2020) developed a multi-period model to design an off-grid micro-hydro power plant based on investment cost, set-up time, and degradation rate. The proposed model determines the economic performance of the power plant and the technical specifications of the equipment, such as the penstock dimensions, turbine choice, weir height, and the selection of a site that meets the local community requirement.

The remaining papers in this issue considered strategies and system design to utilise biomass and wastewater as renewable energy sources. For example, Foong et al. (2020) developed strategies for the production and utilisation of biogas from wastewater from palm oil mill, also known as palm oil mill effluent (POME). PSE tools are applied to synthesise and optimise an integrated biogas and wastewater treatment system with maximum economic performance. According to Foong et al. (2020), the proposed strategy successfully reduces greenhouse gas emissions by 50,430 t CO2e/year as compared to the current practice in the industry. Asni and Andiappan (2020) presented a fuzzy multi-objective optimisation model to design a biomass-combined heat and power system based on contradicting objectives such as system flexibility, reliability, and costs. Unlike the previous work, this paper proposed linear expressions to compute system reliability instead of non-linear equations (Asni and Andiappan 2020). Meanwhile, Saleem et al. (2021) developed an optimisation approach to make systematic design decisions under uncertainty in biomass feedstock supply and heterogeneous composition of biomass. Hurwicz Criterion was used in this paper to design biorefineries based on uncertainties in biomass supply and product demand. Meanwhile, Ching et al. (2021) used artificial intelligence (e.g. artificial neural network, a support vector machine, and an extreme gradient boosting machine) to model and optimise the energy-intensive unit operation (vacuum drying) in algal biofuel production. Lastly, Teh et al. (2021) developed an integrated framework that combined VIKOR, which is a multicriteria decision-making tool with stability analysis. The integrated framework was used to rank candidate configurations for a palm oil ecoindustrial park that produced nanocrystalline cellulose from palm oil biomass.

Acknowledgements The guest editors would like to acknowledge the excellent support of the PIOS editorial office in managing this special issue. Guest editors would also like to give special thanks to all the reviewers for their efforts in ensuring high-quality research work for this special issue.

\section{References}

Andiappan V (2017) State-Of-the-art review of mathematical optimisation approaches for synthesis of energy systems. Process Integr Optim Sustain 1:165-188

Asni T, Andiappan V (2020) Optimal design of biomass combined heat and power system using fuzzy multi-objective optimisation: considering system flexibility, reliability, and cost. Process Integr Optim Sustain. https://doi.org/10.1007/s41660-020-00137-4

Ching PML, Mayol AP, San Juan JLG, Calapatia AM, So RHY, Sy CL, Ubando AT, Culaba AB (2021) AI methods for modeling the vacuum drying characteristics of Chlorococcum infusionum for algal biofuel production. Process Integr Optim Sustain. https://doi.org/10. 1007/s41660-020-00145-4

Foong SZY, Chong MF, Ng DKS (2020) Strategies to promote biogas generation and utilisation from palm oil mill effluent. Process Integr Optim Sustain. https://doi.org/10.1007/s41660-020-00121-y

Hernandez JC, Peñas CJ, Tiu AR, Sy C (2020) A multi-period optimization model for the design of an off-grid micro hydro power plant with profitability and degradation considerations. Process Integr Optim Sustain. https://doi.org/10.1007/s41660-020-00136-5

Leng C, Kong S, Lim JS, Walmsley TG, Liew PY, Goto M (2021) Stagnation and solar fraction analysis on solar thermal integration in Southeast Asia. Process Integr Optim Sustain. https://doi.org/10. 1007/s41660-021-00165-8

Lizárraga-Morazán JR, Picón-Núñez M (2021) Robust design approach for low-temperature solar thermal utility systems. Process Integr Optim Sustain. https://doi.org/10.1007/s41660-021-00167-6

Saleem NN, Yin NL, Andiappan V (2021) Process synthesis of biorefineries under uncertain feedstock conditions based on Hurwicz Criterion. Process Integr Optim Sustain. https://doi.org/ 10.1007/s41660-020-00143-6

Teh KC, Lim SC, Andiappan V, Chew IML (2021) Process integration and optimization for sustainability evaluation of palm oil ecoindustrial park configurations: VIKOR with stability. Process Integr Optim Sustain. https://doi.org/10.1007/s41660-021-00168-5

Ten JY, Liew ZH, Oh XY, Hassim MH, Chemmangattuvalappil N (2021) Computer-aided molecular design of optimal sustainable solvent for liquid-liquid extraction. Process Integr Optim Sustain. https://doi.org/10.1007/s41660-021-00166-7

UN Framework Convention on Climate Change (2015) Historic Paris Agreement on Climate Change: 195 nations set path to keep temperature rise well below 2 degrees celsius. https://unfccc.int/news/ finale-cop21. Accessed 12.3.18

Publisher's Note Springer Nature remains neutral with regard to jurisdictional claims in published maps and institutional affiliations. 